Tohoku J. Exp. Med., 1994, 173, 405-411

\title{
The Pattern of Respiratory Infection in Patients with Lung Cancer
}

\author{
Shigeru Kohno, Hironobu Koga, Mikio Oka, Jyun-ichi \\ Kadota, Mitsuo Kaku, Hiroshi Soda, Kazunori \\ Tomono and KoHei Hara \\ The Second Department of Internal Medicine, Nagasaki \\ University School of Medicine, Nagasaki 852
}

\begin{abstract}
Kohno, S., Koga, H., Oka, M., Kadota, J., Kaku, M., Soda, H., Tomono, K. and Hara, K. The Pattern of Respiratory Infection in Patients with Lung Cancer. Tohoku J. Exp. Med., 1994, 173 (4), 405-411 — We examined retrospectively the pattern of respiratory infection in 579 patients with lung cancer admitted to Nagasaki University Hospital during the past 15 years. A total of 139 patients $(24.0 \%)$ developed respiratory infection. The rates of pulmonary infection associated with large $(36.2 \%)$ and small cell carcinomas $(33.6 \%)$ were significantly higher than those with squamous cell carcinoma (26.0\%) and adenocarcinoma $(17.3 \%)$. Advanced stages of lung cancer were associated with higher complication rates (stage I: $6.3 \%$, stage II: $15.9 \%$, stage III: $27.9 \%$, and stage IV: $33.8 \%$ ). Deceased patients showed a significantly higher rate of pulmonary infection than alive patients during the period of investigation. Isolated organisms in excess of $10^{7} \mathrm{cfu} / \mathrm{ml}$ in sputum or $10^{4} \mathrm{cfu} / \mathrm{ml}$ in bronchial aspirate were mainly gramnegative bacteria $(68.8 \%$ ), such as Haemophilus influenzae, Klebsiella pneumoniae, Enterobacter cloacae, Acinetobacter sp. and Pseudomonas aeruginosa. The number of patients infected with gram-positive bacteria increased markedly after 1982. Our results suggest that a successful control of pulmonary infection associated with lung cancer is important in improving the prognosis of lung malignancy.

lung cancer; pneumonia; gram-positive bacteria; glucose-nonfermenting gramnegative rods
\end{abstract}

Cancer is the leading cause of death in Japan, and the rate of lung cancer has been increasing rapidly in the last few years. Respiratory infection is still one of the main causes of death in patients with lung cancer despite the development of new antimicrobial drugs and chemotherapy for cancer. The pattern of pulmonary infection is changing due to longevity of people afflicted with lung cancer and the immunocompromised patient (Hara 1992). We examined, retrospectively, the incidence and characteristics of respiratory infection complicating lung cancer in a group of patients admitted to Nagasaki University Hospital during a period of 15 years.

Received February 7, 1994; revision accepted for publication July 15, 1994.

Address for reprints: Shigeru Kohno, M.D., The Second Department of Internal Medicine, Nagasaki University School of Medicine, 1-7-1 Sakamoto, Nagasaki 852, Japan. 


\section{Patients And Methods}

The medical records of a total of 579 patients with lung cancer seen at the Second Department of Internal Medicine, Nagasaki University from January 1978 to December 1992 were examined in detail. The population sample consisted of 438 males and 141 females (median age: 63 years). Lung cancer was classified into 4 stages at the time of admission; 139 patients with stage I, 44 patients with stage II, 183 patients with stage III, and 213 patients with stage IV. Histological examination revealed 278 patients had adenocarcinoma, 150 patients had squamous cell carcinoma, 104 patients with small cell carcinoma, and 47 patients with large cell carcinoma. In addition to these tumors, three patients had another lung tumor of adenoid cystic carcinoma, mucoepidermoid carcinoma or mixed tumor. A sudden development of a productive cough with purulent sputum was associated with fever and the appearance of an infiltrate on chest roentgenogram. These features were associated with dullness and rales on physical examination. The presence of these criteria was consistent with acute respiratory infection. Infections occurring in other locations, such as generalized septicemia or urinary tract infection, were not included in the present study.

A thorough examination of reported symptoms, chest roentgenogram, pertinent laboratory data related to acute phase reactants, and the type of isolated organisms from sputum or bronchial aspirate, was performed in patient with pulmonary infection and lung cancer. The relationship between infection and several parameters related to lung cancer, such as stage, type, treatment, and prognosis, was also examined.

Statistical analysis was performed using the chi-square test.

\section{RESULTS}

A total of 139 patients $(24.0 \%)$ developed pulmonary infection during hospitalization. There was no significant difference in the complication rate between males $(111 / 438,25.3 \%)$ and females $(28 / 141,19.8 \%)$. A chronological comparison between the first 5 and last 5 years of investigation showed a significant decrease in pulmonary infection, from $25-35 \%$ to $10-20 \%(p<0.01)$.

Histological survey disclosed that large $(17 / 47,36.2 \%)$ and small cell carcinomas $(35 / 104,33.6 \%$ ) were associated with higher rates of infection than squamous cell carcinoma $(39 / 150,26.0 \%)$ and adenocarcinoma (48/278, 17.3\%). This meant that small cell carcinoma was associated with higher rates of pulmonary infection than non-small cell carcinoma (104/475, 21.9\%). Three patients with double lung cancer did not develop pulmonary infection. A total of 582 episodes of infection were analyzed. The rate of lung infection significantly increased with worsening of pulmonary malignancy $(p<0.01)$, i.e., the more advanced the tumor was, the higher the rate of infection. The infection rates were $6.5 \%(9 / 139)$ in stage I, $15.9 \%(7 / 44)$ in stage II, $27.9 \%(51 / 183)$ in stage III, 
and $33.8 \%$ (72/213) in stage IV. Deceased patients had significantly higher rates of infection than those surviving lung cancer, improving or showing no change following therapy. This was true for each stage of lung cancer (Table 1).

Clinical and laboratory data were analyzed in 148 episodes of pulmonary infection, including 9 patients who developed two episodes of infection during hospitalization. The type of infection was as follows: 139 pneumonia, 5 purulent pleuritis, 2 empyema, 1 pulmonary abscess, and 1 pulmonary aspergillosis. Fever was recorded in 143 of 148 patients $(96.6 \%)$ and purulent sputum was expectorated in 68 of 148 patients $(45.9 \%)$. The rates of positive inflammatory reaction included $55.9 \%$ associated with leukocytosis $\left(>10,000 / \mathrm{mm}^{3}\right), 77.6 \%$ with neutrophilia $(>60 \%), 97.9 \%$ with $\mathrm{CRP}(>+), 95.0 \%$ associated with an erythrocyte sedimentation rate higher than $>21 \mathrm{~mm} / \mathrm{hr}, 91.1 \%$ associated with mucoprotein $(>110 \mathrm{mg} / 100 \mathrm{ml})$, and $52.2 \%$ with $\alpha 2$-globulin $(>10.1 \%)$. Chest roentgenogram showed new shadows consisting of non-obstructive infiltrative shadows in 85 of 148 episodes of pulmonary infection $(57.4 \%$ ), obstructive shadows in 40 $(27.0 \%)$, micronodular in $3(2.0 \%)$, and pleural effusion in $7(4.7 \%)$ episodes of infection.

Microbiological study of the sputum and bronchial aspirate showed 170 positive isolated organisms $\left(>10^{7} / \mathrm{ml}\right.$ in sputum and $>10^{4} / \mathrm{ml}$ in bronchial aspirate) in 111 out of 148 episodes. The majority of cultured organisms were gram-negative bacteria ( $n=117,68.8 \%$ ), followed by gram-positive bacteria $(n=$ $33,19.4 \%)$, anaerobes $(n=3,1.8 \%)$, and fungi $(n=17,10 \%)$. Major isolated pathogens included Haemophilus influenzae, Klebsiella pneumoniae, Enterobacter cloacae, Acinetobacter sp., Pseudomonas aeruginosa, and Staphylococcus aureus. Chronological change in isolated organisms in each of 5 year period of observation showed a progressive increase in gram-positive bacteria from $4.1 \%$ to $28.3 \%$ to

TABLE 1. The incidence of infection classified according to prognosis and cancer stage

\begin{tabular}{ccccc}
\hline \multirow{2}{*}{ Stage } & \multicolumn{3}{c}{ Prognosis } \\
\cline { 2 - 4 } & \multicolumn{3}{c}{ Alive } & Deceased \\
\cline { 2 - 4 } & Operation & Improved & Unchanged/Aggravated & $3 / 8$ \\
\hline I & $2 / 105$ & $3 / 9$ & $1 / 17$ & $(37.5)$ \\
& $(1.9)$ & $(33.3)$ & $(5.9)$ & $2 / 3$ \\
II & $2 / 20$ & $2 / 10$ & $1 / 11$ & $(66.7)$ \\
& $(10.0)$ & $(20.0)$ & $(9.1)$ & $24 / 34$ \\
III & $2 / 40$ & $11 / 48$ & $14 / 61$ & $(70.6)$ \\
& $(5.0)$ & $(22.9)$ & $(23.0)$ & $51 / 80$ \\
IV & $1 / 4$ & $7 / 37$ & $13 / 92$ & $(63.8)$ \\
& $(25.0)$ & $(18.9)$ & $(14.1)$ & $80 / 125$ \\
Total & $7 / 169$ & $23 / 104$ & $29 / 181$ & $(64.0)$ \\
& $(4.1)$ & $(22.1)$ & $(16.0)$ & \\
\hline
\end{tabular}

Numbers in parentheses represent the percentage of patients in each category. 
TABLE 2. Isolated organisms from the respiratory tract in infected patients with lung cancer

\begin{tabular}{|c|c|c|c|c|}
\hline & $1978-82$ & $1983-87$ & 1988-92 & Total \\
\hline S. pneumoniae & 1 & 2 & - & 3 \\
\hline S. mitis & - & 1 & 4 & 5 \\
\hline S. haemolyticus & -1 & 1 & - & 1 \\
\hline S. simurans & - & 1 & 3 & 4 \\
\hline$\beta$-streptococcus & - & 2 & 2 & 4 \\
\hline S. aureus & 2 & 7 & 3 & 12 \\
\hline E. faecalis & - & 2 & 1 & 3 \\
\hline E. faecium & - & 1 & - & 1 \\
\hline Gram-positive & $\begin{array}{c}3 \\
(4.1)\end{array}$ & $\begin{array}{c}17 \\
(28.3)\end{array}$ & $\begin{array}{c}13 \\
(36.1)\end{array}$ & $\begin{array}{c}33 \\
(19.4)\end{array}$ \\
\hline M. catarrhalis & - & 1 & 1 & 2 \\
\hline H. Influenzae & 11 & 7 & 1 & 19 \\
\hline H. parahaemolyticus & 3 & 1 & 2 & 6 \\
\hline H. parainfluenzae & 4 & 2 & 2 & 8 \\
\hline E. coli & 5 & 1 & - & 6 \\
\hline K. pneumoniae & 12 & 1 & 3 & 16 \\
\hline K. oxytoca & - & 1 & - & 1 \\
\hline S. marcescens & 4 & 1 & - & 5 \\
\hline E. cloacae & 11 & 6 & - & 17 \\
\hline E. agglomerans & 1 & 1 & - & 2 \\
\hline X. maltophilia & - & - & 3 & 3 \\
\hline Acinetobacter sp. & 5 & 9 & 2 & 16 \\
\hline P. aeruginosa & 8 & 7 & - & 15 \\
\hline Flavobacterium sp. & - & 1 & - & 1 \\
\hline Gram-negative & $\begin{array}{c}64 \\
(86.5)\end{array}$ & $\begin{array}{c}39 \\
(65.0)\end{array}$ & $\begin{array}{c}14 \\
(38.8)\end{array}$ & $\begin{array}{c}117 \\
(68.8)\end{array}$ \\
\hline B. asaccharolytics & - & 1 & - & 1 \\
\hline Corynebacterium sp. & - & - & 2 & 2 \\
\hline Aspergillus fumigatus & - & - & 1 & 1 \\
\hline Candida albicans & 4 & 3 & 4 & 11 \\
\hline C. tropicalis & 1 & - & - & 1 \\
\hline C. glabrata & - & - & 1 & 1 \\
\hline Cytomegalovirus & 2 & - & 1 & 3 \\
\hline Others & $\begin{array}{c}7 \\
(9.5)\end{array}$ & $\begin{array}{c}4 \\
(6.7)\end{array}$ & $\begin{array}{c}9 \\
(25.0)\end{array}$ & $\begin{array}{c}20 \\
(11.8)\end{array}$ \\
\hline Total & 74 & 60 & 36 & 170 \\
\hline
\end{tabular}

Numbers in parentheses represent percentages to the total. 
$36.1 \%$ and a decrease in gram-negative bacteria from $86.5 \%$ to $65.0 \%$ to $38.9 \%$ in 1978-82, 1983-87 and 1988-92, respectively (Table 2).

\section{DiscUssion}

The development of infection in patients with malignancy may represent a diagnostic enigma since the presence of fever and a positive CRP could be a manifestation of the cancer itself. One of the most important clinical features of pulmonary infection is the new appearance of radiological chest shadows, which are not due to radiation pneumonitis or lung cancer itself. In this regard, chest computed tomography (CT) is a better test than plain chest $\mathrm{x}$-ray as it is capable of detecting faint shadows that are invisible on chest $\mathrm{x}$-rays. The presence of fever, leukocytosis, neutrophilia and positive CRP are also suggestive of infection, particularly when a progression of tumor malignancy is ruled out. The rates of respiratory infection complicating lung cancer were reported to be $51.4 \%$ (Watanabe et al. 1992) and 37.8\% (Konno et al. 1985). These rates are higher than those reported in the present study. On the other hand, Kikuchi (Kikuchi and Watanabe 1984) reported that obstructive pneumonia was observed in $18.3 \%$ of patients with lung cancer while opportunistic infection occurred in $21.6 \%$, results similar to those reported in the present study. The different rates may reflect differences in the stage of lung cancer, the use of antineoplastic therapy, such as chemotherapy and radiation, or the use of different definitions of infection. The rate of infection correlated well with the clinical stage of cancer in the present study. Furthermore, Oizumi and colleagues (Oizumi et al. 1985) reported higher rates of obstructive pneumonia at or immediately after admission to the hospital, and that the rate of pulmonary infection increased with a reduction in obstructive pneumonia in response to the administration of anti-neoplastic therapy. This was followed by increased rate of obstructive pneumonia and respiratory infection due to a progression of bronchial obstruction and depression of immunity observed at the terminal stage of lung cancer. Bronchial obstruction is more common in squamous and small cell carcinomas than in adenocarcinoma and large cell carcinoma. Furthermore, the rate of obstructive pneumonia in stages III and IV of lung cancer is higher in squamous $(36.5 \%)$ than small cell carcinoma $(15.6 \%)$ and adenocarcinoma (5.8\%) (Kikuchi and Watanabe 1984). However, bronchial obstruction was not directly related to pulmonary infection since undifferentiated carcinoma, such as small and large cell carcinomas, was associated with a high incidence of respiratory infection. This relation may suggest that the rapid growth of cancer and intensive antitumor therapy play an important role in the development of pulmonary infection.

Determination of the exact organism causing respiratory infection is generally difficult. We used a cutoff count of $10^{7} \mathrm{cfu} / \mathrm{ml}$ in sputum and $10^{4} \mathrm{cfu} / \mathrm{ml}$ in bronchial aspirate as criteria to define significant isolates (Monroe et al. 1969; Pirtle et al. 1969; Wimberley et al. 1982; Hara et al. 1985). The isolated organ- 
isms consisted of gram-negative $(68.8 \%)$, gram-positive $(19.4 \%)$ bacteria and $11.8 \%$ of fungi and anaerobes. Abeloff et al. (1983) reported that $E$. coli, Klebsiella spp., $P$. aeruginosa, and S. aureus were the four major pathogens causing respiratory infection in association with lung cancer. Our results showed more Acinetobacter sp. and $E$. cloacae with only a small percentage of $E$. coli.

The number of patients with isolated gram-negative bacteria was markedly reduced after 1982. This may probably be related to the increased use of third generation cephems in Japan. These compounds are less potent against grampositive bacteria than first and second generation cephems. However, the antimicrobial activity against glucose-nonfermenting gram-negative rods is not generally strong enough to completely eradicate these organisms.

Infection could be an important cause of death in lung cancer (Rubin 1980; Markman and Abeloff 1983; Oizumi at al. 1989; Zvetina et al. 1992). Our results demonstrated a high incidence of pulmonary infection in deceased patients and a low incidence of infection in patients treated surgically. This observation is probably due to the general status of cancer patients and the degree of immunosuppression. It is usually difficult to treat patients with lung cancer, especially in advanced stages, and the control of infection may be an important clinical step in improving the prognosis of lung cancer.

\section{References}

1) Abeloff, M.D., Klastersky, J., Drings, P.D., Eagan, R.T., Greco, F.A., Holsti, L., Mattson, K. \& Postmus, P.E. (1983) Complication of treatment of small cell carcinoma of the lung. Cancer Treat. Rep., 67, 21-26.

2) Hara, K. (1992) Changes of infection. Pharma Medica, 10, 119-130. (in Japanese)

3) Hara, K., Yamaguchi, K., Shigeno, Y., Suzuyama, Y., Tomonaga, A., Kanda, T., Izumikawa, K., Hirota, M. \& Saito, A. (1985) Bacteriological evaluation of materials obtained by fiberoptic bronchoscopy in cases of pulmonary infection. Jpn. J. Thorac. Dis., 23, 463-472. (in Japanese)

4) Kikuchi, N. \& Watanabe, S. (1984) Pulmonary infection associated with lung cancer. Kokyu, 3, 660-665. (in Japanese)

5) Konno, K., Sasaki, A. \& Oizumi, K. (1985) Infection associated with malignant tumor. Tiryo, 67, 901-906. (in Japanese)

6) Markman, M. \& Abeloff, M. (1983) Management of hematologic and infectious complications of intensive induction therapy for small cell carcinoma of the lung. Am. J. Med., 74, 741-746.

7) Monroe, P.W., Muchmore, H.G., Felton, F.G. \& Pirtle, J.K. (1969) Quantitation of microorganisms in sputum. Appl. Microbiol., 18, 214-220.

8) Oizumi, K., Sasaki, S., Watanabe, A., Aonuma, S., Onuma, K., Otani, N., Sasaki, R. \& Konno, K. (1985) Infection of lung cancer and its control. Gan no Rinsyo, 31, 1203-1210. (in Japanese)

9) Oizumi, K., Ono, R., Konno, K. \& Numazaki, Y. (1989) Isolation of cytomegalovirus from the lung tissue of patients with intrapulmonary neoplasms. Tohoku J. Exp. Med., 158, 335-336.

10) Pirtle, J.K., Monroe, P.W., Smalley, T.K., Mohr, J.A. \& Rhoades, E.R. (1969) Diagnosis and therapeutic advantages of serial quantitative cultures of fresh sputum in acute bacterial pneumonia. Am. Rev. Respir. Dis., 100, 831-838. 
11) Rubin, R.H. (1980) The cancer patients with fever and pulmonary infiltrates: Etiology and diagnostic approach. In: Current Clinical Topics in Infectious Diseases, edited by A. Remington, McGraw-Hill Book Corp., New York, pp. 288-303.

12) Watanabe, A., Nakai, Y., Saito, J., Honda, Y., Tokue, Y., Sugawara, S., Numata, Y., Kikuchi, T., Sato, J. \& Matsubara, N. (1992) Clinical significance of respiratory infections associated with lung cancer patients. Jpn. J. Thorac. Dis., 10, 1250-1256. (in Japanese)

13) Wimberley, N.W., Bass, J.B., Boyd, B.W., Kirkpatrick, M.B., Serio, R.A. \& Pollock, H.M. (1982) Use of a bronchoscopic protected catheter brush for the diagnosis of pulmonary infections. Chest, 81, 556-562.

14) Zvetina, J.R., Maliwan, N., Frederick, W.S. \& Reyes, C. (1992) Mycobacterium kansasii infection following primary pulmonary malignancy. Chest, 102, 1460-1463. 